\title{
The first 24-hour bilirubin level as a predictor of hyperbilirubinemia in healthy term newborns
}

\author{
Rina Triasih, MD; Ekawaty L Haksari, MD; Achmad Surjono, MD
}

\begin{abstract}
Background Early discharging healthy term newborns results in a difficulty to recognize hyperbilirubinemia.

Objective The aim of this study was to determine the value of the first 24-hour total and unbound bilirubin levels in predicting hyperbilirubinemia in healthy term newborns.

Methods The first 24-hour and the $5^{\text {th }}$ day total and unbound bilirubin levels were measured in 84 healthy term newborns. The total bilirubin level was measured spectrophotometrically, whereas unbound bilirubin level was determined by peroxidase-oxidation method. Hyperbilirubinemia was defined as serum total bilirubin of $\geq 12.9 \mathrm{mg} / \mathrm{dL}$ or serum unbound bilirubin of $\geq 0.5 \mathrm{mg} / \mathrm{dL}$ after 24 hours of life.

Results A correlation between the first 24-hour and the $5^{\text {th }}$ day total bilirubin levels was found $(r=0.53)$ with a regression equation: $Y$ (total bilirubin on day 5$)=4.69+1.15 X$ (total bilirubin in the first 24 hours). In unbound bilirubin $(r=0.31)$, the regression equation was $Y$ (unbound bilirubin on day 5 ) $=0.13+0.95 X$ (unbound bilirubin in the first 24-hours). The relative risk for developing hyperbilirubinemia in newborns whose $\mathrm{TB}_{1}$ was $\geq 4.5 \mathrm{mg} / \mathrm{dL}$ was 12 $(95 \% \mathrm{Cl} 2.9 ; 48.4)$, whereas newborns whose $\mathrm{UB}_{1}$ was $\geq 0.09 \mathrm{mg} /$ $\mathrm{dL}$ was $9.5(95 \% \mathrm{Cl} 1.2 ; 77.4)$.

Conclusion Total bilirubin level of $\geq 4.5 \mathrm{mg} / \mathrm{dL}$ in the first 24 hours can predict the development of hyperbilirubinemia in term newborns in the first week of life. Newborns with such level of total bilirubin need a longer stay or should visit the hospital on day 5-7 [Paediatr Indones 2003;43:85-90].
\end{abstract}

Keywords: first day bilirubin level, neonatal hyperbilirubinemia

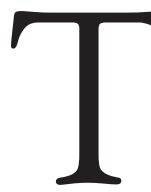

The tendency to early discharge healthy term newborns is now increasing because of some medical, social, and economic reasons. Some studies reported that early discharge is related to a risk of hospital readmission, and that the most common cause of readmission during the early neonatal period is hyperbilirubinemia. ${ }^{1-4}$ Visual recognition in estimating the jaundice severity is inaccurate and varies with the level of training of the nurses, resident physicians and attending staffs. ${ }^{5}$ Moreover, asking mothers to observe their infants for the development of jaundice is not accountable; it may be difficult for some parents to recognize significant jaundice. Thus, it is difficult to recognize, follow-up, and perform early treatment of hyperbilirubinemia as the result of early newborn hospital discharge. The danger of failing to recognize and treat neonatal hyperbilirubinemia following early discharge had been confirmed by reports of kernicterus in full-term healthy newborns with no apparent hemolysis, without jaundice in the first 24 hours, and no cause for hyperbilirubinemia. ${ }^{5-8}$ Therefore early identification of newborns at risk for developing severe hyperbilirubinemia and possible bilirubin-induced neurologic dysfunction has become a necessity. The practice parameter for the management of hyperbilirubinemia in the healthy newborn infant published in 1994 by the American Academy of Pediatrics recommended that a serum bilirubin examination should be done in any infants noted to

From the Department of Child Health, Medical School, Gadjah Mada University, Sardjito General Hospital, Yogyakarta.

Reprint requests to: Rina Triasih, MD, Department of Child Health, Medical School, Gadjah Mada University, Sardjito General Hospital, Yogyakarta, Indonesia. Tel. 62-274-561616, Fax. 62-274-583745. 
be jaundiced by visual assessment in the first 24 hours after birth. It also stated that follow-up by a healthcare professional should be scheduled within 2 to 3 days for all neonates discharged less than 48 hours after birth ${ }^{9}$. The need for measurement of serum bilirubin at follow-up depends on the judgment of the professional providing care, based on his or her visual estimation of the severity of jaundice. Unfortunately, unless the visual estimation of the severity of jaundice is fairly accurate and there is a concern about its intensity, bilirubin levels can rise to a dangerous level.

Recent studies suggested that determining total serum bilirubin in the first 24 hours of life could help to recognize infants at risk. ${ }^{10-12}$ However, in the management of neonatal hyperbilirubinemia, the concentration of total bilirubin is not specifically significant to predict the brain damage due to bilirubin toxicity. An association between unbound bilirubin and kernicterus had been discussed in several studies. ${ }^{13}$ ${ }^{14}$ The aim of the present study was to prospectively determine the ability of the first 24-hour total and unbound bilirubin levels (TB and UB) to predict hyperbilirubinemia in term healthy newborns in the first week of life.

\section{Methods}

The study was performed in the newborn nursery of the Sardjito General Hospital, Yogyakarta, from December 2000 to March 2001. All healthy full-term (37-42 weeks of gestation as determined by Dubowitz score) and appropriate for gestational age newborns (based on the Indonesian intrauterine weight growth curve ${ }^{15}$ ) and with an Apgar score of more than 6, were prospectively enrolled in the study. Infants with sepsis, $\mathrm{ABO}$ incompatibility, signs of hemolytic tendencies, or had no complete TB and UB measurements, were excluded from the study. Informed consents were obtained from the parents. All subjects were cared with the rooming-in method to ensure the practice of exclusive breastfeeding.

Hematocrit (Hct), total bilirubin (TB), and unbound bilirubin (UB) levels were initially measured within the first 24 hours of life $\left(\mathrm{Hct}_{1}, \mathrm{~TB}_{1}, \mathrm{UB}_{1}\right)$ and were repeated on the $5^{\text {th }}$ day $\left(\mathrm{Hct}_{5}, \mathrm{~TB}_{5}, \mathrm{UB}_{5}\right)$. In some, earlier measurement were performed $\left(\mathrm{Hct}_{3}\right.$, $\mathrm{TB}_{3}, \mathrm{UB}_{3}$ ) for clinical reasons (clinical jaundice
Kramer III-V before day 5). Parents whose infants were discharged early, were suggested to visit the lactation clinic in the outpatient department on the $5^{\text {th }}$ day, or as soon as their infants appeared jaundiced. Gender, birth weight, gestational age, maternal age, delivery route, Apgar scores, rupture of the membranes, and feeding pattern were recorded in all subjects.

Capillary blood samples were drawn by heel stick for checking the levels of Hct, TB, and UB. In order to avoid the influence of light, care was taken by covering the serum collecting tubes with aluminum foil. An amount of $20 \mathrm{~mL}$ of serum was required for the TB and UB measurements. TB level was measured spectrophotometrically and UB level was determined by peroxidase-oxidation method at room temperature of $30^{\circ} \mathrm{C}$ using UB-analyzer UAF-2 (Arrows Co Ltd., Osaka). Newborns with TB level of $\geq 12.9 \mathrm{mg} / \mathrm{dL}$ or UB level of $\geq 0.5 \mathrm{mg} / \mathrm{dL}$ after 24 hours of life were defined as having hyperbilirubinemia, and they had to undergo phototherapy if their TB level was $\geq 20 \mathrm{mg} / \mathrm{dL}$ or UB level was $\geq 0.7 \mathrm{mg} /$ $\mathrm{dL}$ on follow up.

Data were statistically analyzed with the independent sample $t$ test and $X^{2}$ analysis for comparison of the clinical data between the hyperbilirubinemia and non-hyperbilirubinemia groups. The critical $\mathrm{TB}_{1}$ and $\mathrm{UB}_{1}$ levels with high sensitivity and high specificity were determined with the receiver operating characteristic (ROC) curve analysis. The correlations between TB1 and TB5 as well as UB1 and UB5 for all enrolled infants were found by the linear regression analysis. The relative risks with $95 \%$ confidence interval (CI) were calculated to find out the risk of hyperbilirubinemia among the newborns whose $\mathrm{TB}_{1}$ or $\mathrm{UB}_{1}$ exceeded the critical levels.

\section{Results}

Of the 84 infants enrolled in this study, 20 (24\%) had $\mathrm{TB}_{5} \geq 12.9 \mathrm{mg} / \mathrm{dL}$ and $6(7 \%)$ had $\mathrm{UB}_{5} \geq 0.5$ $\mathrm{mg} / \mathrm{dL}$. The distribution of the maternal and neonatal categorical characteristics and the incidence of hyperbilirubinemia according to each variable are presented in Table 1 . There was no significant difference between subjects that developed and did not develop hyperbilirubinemia in respect to various factors that may be associated 
Rina Triasih et al: The first 24-hour bilirubin level as a predictor of hyperbilirubinemia

TABLE 1. THE CHARASTERISTICS OF HYPERBILIRUBINEMIA AND NON-HYPERBILIRUBINEMIA SUBJECTS

\begin{tabular}{|c|c|c|}
\hline & $\begin{array}{l}\text { Hyperbilirubinemia (+) } \\
n=20\end{array}$ & $\begin{array}{l}\text { Hyperbilirubinemia (-) } \\
n=64\end{array}$ \\
\hline Hematocrit day $1(\%)^{\star}$ & 58.6 & 56.5 \\
\hline Hematocrit day $5(\%)^{*}$ & 54.14 & 51.5 \\
\hline Gestational age $(w k)^{\star}$ & 38.82 & 39.00 \\
\hline Birth weight $(\mathrm{g})^{\star}$ & 2947.73 & 2940.49 \\
\hline Vaginal delivery ${ }^{\dagger}$ & 14 & 48 \\
\hline Breastfed $^{\dagger}$ & 19 & 55 \\
\hline Maternal age (years)* & 28.35 & 28.81 \\
\hline Rupture of membranes $(\mathrm{hr})^{\star}$ & 9.41 & 11.72 \\
\hline
\end{tabular}

with the risk of hyperbilirubinemia, such as hematocrit level, gestational age, birth weight, delivery mode, maternal age, rupture of the membranes, and feeding pattern.

Figure 1 and 2 showed the correlation between the first 24-hour TB/UB and the $5^{\text {th }}$ day TB/UB. There was a correlation between $\mathrm{TB}_{1}$ and $\mathrm{TB}_{5}$ levels $(\mathrm{r}=0.53)$ with a regression equation as $\mathrm{Y}\left(\mathrm{TB}_{5}\right)=4.69+1.15 \mathrm{X}$ $\left(\mathrm{TB}_{1}\right)$. For unbound bilirubin $(\mathrm{r}=0.31)$, the regression equation was $\mathrm{Y}\left(\mathrm{UB}_{5}\right)=0.13+0.95 \mathrm{X}\left(\mathrm{UB}_{1}\right)$.

By ROC analysis, the level of $\mathrm{TB}_{1}$ of $\geq 4.5 \mathrm{mg} /$ $\mathrm{dL}$ was determined to have a high sensitivity $(90.0 \%)$ and a high specificity (71.9\%), whereas the level of $\mathrm{UB}_{1}$ of $\geq 0.09 \mathrm{mg} / \mathrm{dL}$ had a sensitivity of $83.3 \%$ and a specificity of $69.2 \%$ to predict newborns who would develop hyperbilirubinemia (Figure 3 and 4).

The relative risk for developing hyperbilirubinemia in newborns whose $\mathrm{TB}_{1}$ was $\geq 4.5 \mathrm{mg} / \mathrm{dL}$ was 12

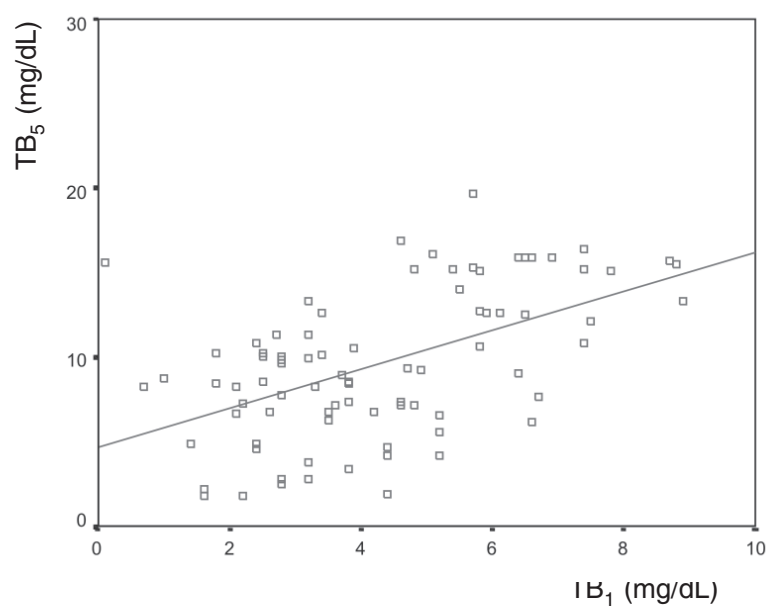

Figure 1. Correlation between $\mathrm{TB}_{1}$ and $\mathrm{TB}_{5}$ levels
(95\% CI 2.9;48.4), whereas newborns whose $\mathrm{UB}_{1}$ was $\geq 0.09 \mathrm{mg} / \mathrm{dL}$ was 9.5 (95\% CI 1.2;77.4). The mean of $\mathrm{TB}_{1}$ in the infants who developed hyperbilirubinemia was significantly higher than that in the infants who did not develop hyperbilirubinemia, but the mean of $\mathrm{UB}_{1}$ between the hyperbilirubinemia and non-hyperbilirubinemia infants was not significantly different (Table 2).

\section{Discussion}

In this study the first 24-hour and the $5^{\text {th }}$ day total and unbound bilirubin levels in healthy term newborns were analyzed. Measurement of unbound bilirubin level which was specific enough to predict the brain damage caused by bilirubin toxicity was the strength of the present study. However, the limited period of

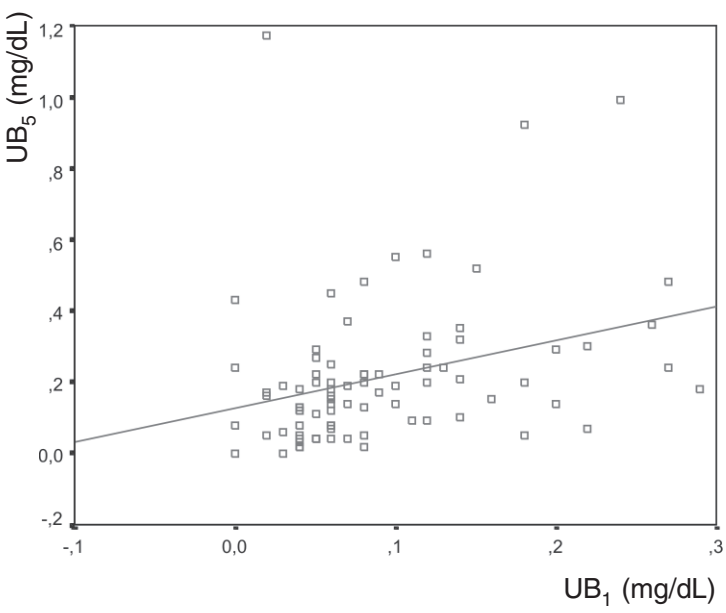

Figure 2. Correlation between $\mathrm{UB}_{1}$ and $\mathrm{UB}_{5}$ level 


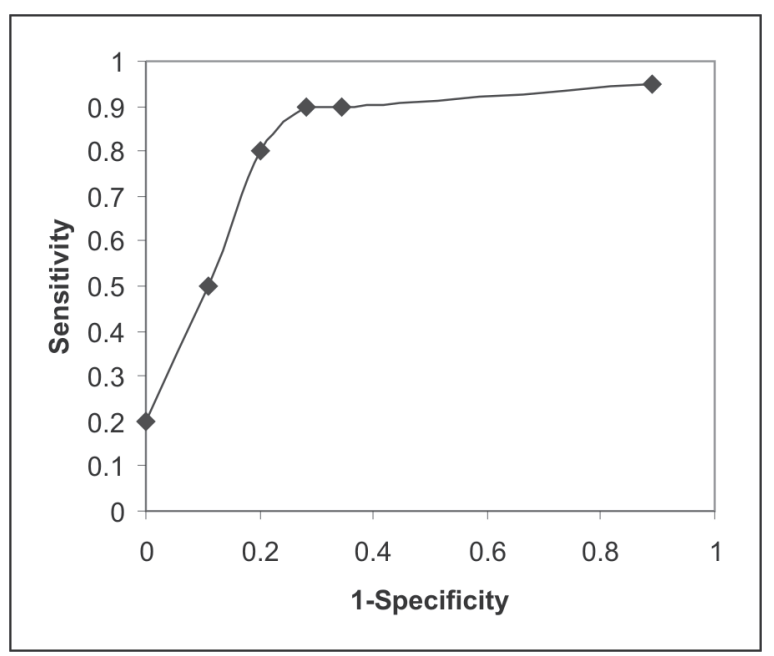

Figure 3. The ROC analysis of the various $\mathrm{TB}_{1}$ level in predicting the development of hyperbilirubinemia

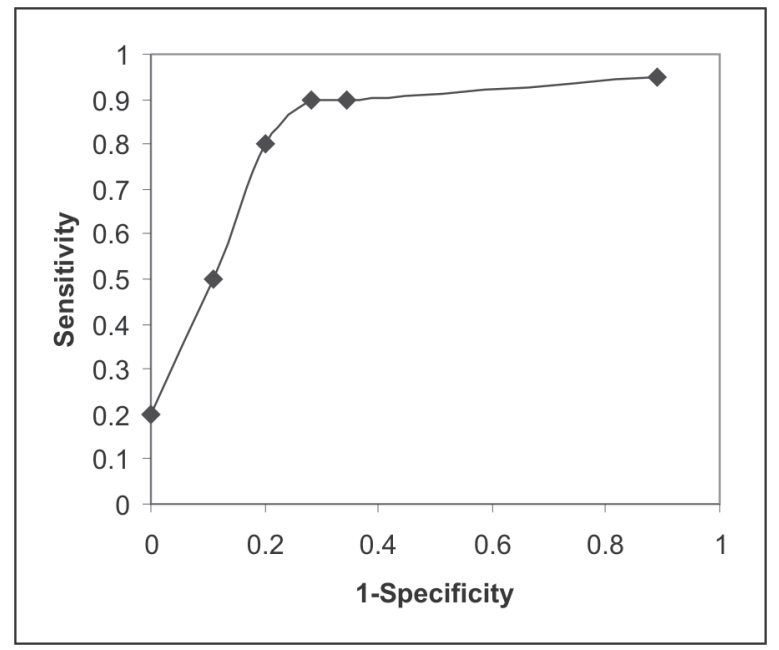

Figure 4. The ROC analysis of the various $\mathrm{UB}_{1}$ level in predicting the development of hyperbilirubinemia

TABLE 2. The TB ${ }_{1}$ AND UB ${ }_{1}$ LEVELS OF HYPERBILIRUBinemiA AND NON-HYPERBILIRUBinemia SUBJECTS

\begin{tabular}{lllll}
\hline & Hyperbilirubinemia (+) & Hyperbilirubinemia (-) & $\mathbf{P}$ & $\mathbf{9 5 \%} \mathbf{C l}$ \\
\hline $\mathrm{TB}_{1}(\mathrm{mg} / \mathrm{dL})$ & $6.06 \pm 2.05$ & $3.70 \pm 1.59$ & 0.000 & $1.50 ; 3.24$ \\
$\mathrm{UB}_{1}(\mathrm{mg} / \mathrm{dL})$ & $0.14 \pm 0.07$ & $0.08 \pm 0.07$ & 0.068 & $0.004 ; 0.11$ \\
\hline
\end{tabular}

Values are given as mean \pm standard deviation

follow up and not daily total and unbound bilirubin measurements were the weakness of our study.

Seidman et al ${ }^{12}$ found that the critical bilirubin level of $5 \mathrm{mg} / \mathrm{dL}$ was reported to have a high specificity $(91.9 \%)$ and low sensitivity $(45.5 \%)$ for detecting hyperbilirubinemia; the positive predictive value was very low $(8.9 \%)$ and the negative predictive value was very high (99\%). In another study, the bilirubin level of $\geq 6 \mathrm{mg} / \mathrm{dL}$ in the first day had sensitivity of $90 \%$ with negative and positive predictive value of $97.9 \%$ and $26.2 \%$, respectively. ${ }^{11} \mathrm{~A}$ similar study found that no infant whose bilirubin level was $<5 \mathrm{mg} / \mathrm{dL}$ at 20 28 hours of life developed hyperbilirubinemia, whereas $33 \%$ of those whose bilirubin level was $\geq 8 \mathrm{mg} / \mathrm{dL}$ developed hyperbilirubinemia. ${ }^{16}$ Our findings showed that a total bilirubin level of $\geq 4.5 \mathrm{mg} / \mathrm{dL}$ in the first 24 hours of life had high sensitivity (90\%) and specificity $(71.9 \%)$, with positive and negative predictive value of $50 \%$ and $96.8 \%$, respectively. These differences may be attributable to ethnic and geographic variations in different populations and laboratory variability in the measurement of bilirubin.
Newborns whose total bilirubin level was $\geq 4.5$ $\mathrm{mg} / \mathrm{dL}$ in the first 24 hours had higher risk of developing hyperbilirubinemia than those whose total bilirubin level was $<4.5 \mathrm{mg} / \mathrm{dL} \quad(\mathrm{RR}=12 ; 95 \% \mathrm{CI}$ 2.9;48.4). In Alpay's study, ${ }^{11}$ of the 206 newborns whose bilirubin level was $\geq 6 \mathrm{mg} / \mathrm{dL}$ in the first 24 hours of life, 26.2\% developed hyperbilirubinemia, whereas only $2.0 \%$ of the 292 newborns, whose bilirubin level were $<6 \mathrm{mg} / \mathrm{dL}$ in the first day of life, developed hyperbilirubinemia $(R R=12.8)$.

Some previous studies ${ }^{17-19}$ showed that breast feeding is related to hyperbilirubinemia, but the others ${ }^{20,21}$ found different results. Some probable factors associated with breast milk jaundice may include the presence of pregnandiol in the breastmilk, ${ }^{22}$ inhibition of glucuronyl-transferase enzyme by long chain fatty acid in the breast milk, ${ }^{23}$ increased concentration of lipoprotein lipase in breast milk that inhibited bilirubin conjugation, ${ }^{24}$ or increased enteric absorption of unconjugated bilirubin due to inadequate intake. 18,19,22 However, the certain mechanism of hyperbilirubinemia in the breastfed infants is still unclear, whether it is 
Rina Triasih et al: The first 24-hour bilirubin level as a predictor of hyperbilirubinemia

related to inadequate intake or the role of specific substances in the breast milk. Almost all of the infants who developed or did not develop hyperbilirubinemia in the present study were given breast milk during hospitalization, and at home. It supports the dictum that there is no reason for not giving breast milk because of the fear of developing hyperbilirubinemia.

Several recent reports ${ }^{5-8}$ showed that kernicterus occasionally occurs in healthy breast or bottlefed infants, born at or near term, and in the absence of any diagnosed complicating factors such as isoimunization or other causes of hemolysis, prematurity, sepsis or any constitutional defects in hepatic bilirubin clearance. It has been suggested that unbound bilirubin is responsible in causing brain damage with its toxicity to membranes of either brain capillary endothelium or neurons in the form of bilirubin acid. ${ }^{13}$ In the present study we also evaluated the value of the first 24 hours unbound bilirubin level in predicting hyperbilirubinemia in healthy term newborns. Although our study showed that unbound bilirubin level of $\geq 0.09 \mathrm{mg} / \mathrm{dL}$ in the first 24 hours of life had high sensitivity and moderate specificity $(83.3 \%$ and $69.2 \%$, respectively), the difference of the first 24 hours unbound bilirubin level in hyperbilirubinemic and non-hyperbilirubinemic infants was not significant. It suggests that we could not use the first 24 hours unbound bilirubin level as a predictor of hyperbilirubinemia in term newborns. These findings also showed that in term newborns, the unbound bilirubin level did not always match the total bilirubin level. Surjono ${ }^{25}$ found 4 groups of infants, i.e., low total bilirubin-low unbound bilirubin, relatively high total bilirubin-low unbound bilirubin, high total bilirubinhigh unbound bilirubin, and low total bilirubin-relatively high unbound bilirubin. The level of unbound bilirubin is related to the bilirubin binding capacity of serum albumin. This binding is influenced by the serum bilirubin level and albumin level, $\mathrm{pH}$, the presence of substances that occupy bilirubin's binding sites on albumin, such as drugs (i.e., aspirin and sulfonamide), fatty acids in nutritional products (e.g. Intralipid ${ }^{\circledR}$ ), asphyxia, sepsis, hypothermia, and hypoglicemia. ${ }^{22}$ In healthy term newborns, the bilirubin-albumin binding capacity is still appropriate.

Ninety percent of healthy term newborns in the study that developed hyperbilirubinemia could be predicted by total bilirubin level of $4.5 \mathrm{mg} / \mathrm{dL}$ in the first
24 hours of life. A 96.8\% negative predictive value in our study also suggests that measurement of total bilirubin level in the first 24 hours of life can help to identify newborns that are unlikely to require further evaluation and intervention. We suggested that newborns with total bilirubin level of $\geq 4.5 \mathrm{mg} / \mathrm{dL}$ in the first 24 hours, should stay longer in the nursery or must visit the hospital on day 5-7.

Based on the findings in the present study, we concluded that a total bilirubin level of $4.5 \mathrm{mg} / \mathrm{dL}$ in the first 24 hours of life will predict nearly all healthy term newborns that will develop hyperbilirubinemia in the first week of life, whereas unbound bilirubin level could not be used as a predictor of hyperbilirubinemia. However, the results of this study are applicable only to healthy term newborns and further studies including larger number of newborns and longer follow up should be carried out.

\section{References}

1. Seidman DS, Stevenson DK, Ergaz Z, Gale R. Hospital readmission due to neonatal hyperbilirubinemia. Pediatrics 1995;96:727-9.

2. Chatz C, Hanson JW, Simpson L, Yaffe SJ. Summary of workshop: early discharge and neonatal Hyperbilirubinemia. Pediatrics 1995;96:743-5.

3. Lee KS, Perlman B, Ballantyne M, Elliot I, To T. Association between duration of neonatal hospital stay and readmission. J Pediatr 1995;127:758-66.

4. Gale R, Seidman DS, Stevenson DK. Hyperbilirubinemia and early discharge. J Perinatol 2001:21:40-3.

5. Johnson L and Bhutani VK. Guidelines for management of the jaundiced term and near-term infant. Clin Perinatol 1998;25:555-73.

6. Penn AA, Enzmann DR, Hah JS, Stevenson DK. Kernicterus in a full-term infant. Pediatrics 1993;93:1003-6.

7. Sola A. Changes in clinical practice and bilirubin encephalopathy in "healthy term newborns". Pediatr Res 1995;37:145A.

8. Maisels MJ, Newman TB. Kernicterus in otherwise healthy, breast-fed term newborns. Pediatrics 1995;96:730-3.

9. American Academy of Pediatrics Practice Parameter. Management of Hyperbilirubinemia in the healthjy term newborn. Pediatrics 1994;94:558-65. 
10. Bhutani VK, Johnson L, Sivieri EM. Predictive ability of a predischarge hour-specific serum bilirubin for subsequent significant hyperbilirubinemia in healthy term and near-term newborns. Pediatrics 1999;103:6-14.

11. Alpay F, Sarici SU, Tosuncuk HD, Serdar MA, Inanc $\mathrm{N}$, Gokcay E. The value of first-day bilirubin measurement in predicting the development of significant hyperbilirubinemia in healthy term newborns. Pediatrics 2000;106:e16.

12. Seidman DS, Ergaz Z, Paz I, Laor A, Revel-Vilk S, Stevenson DK, et al. Predicting the risk of jaundice in fullterm healthy newborns: a prospective population-based study. J Perinatol 1999;19:564-7.

13. Nakamura $\mathrm{H}$, Yonetani M, Uetani Y, Funato M, Lee Y. Determination of serum unbound bilirubin for prediction of kernicterus in low birthweight infants. Acta Pediatr Jpn 1992;34:642-7.

14. Cadhore WJ, Oh W. Unbound bilirubin and kernicterus in low birt weight infants. Pediatrics 1982;69:481-5.

15. Alisjahbana A, Chaerulfatah A, Usman A, Sutresnawati S. Anthropometry of newborn infants born in 14 teaching centers in Indonesia. Pediatr Indones 1994;34:62-123.

16. Bhutani VK, Johnson LH, Sivieri EM. Universal newborn bilirubin screening. Pediatr Res 1997;41:191A.
17. Adams JA, Hey DJ, Hall RT. Incidence of hyperbilirubinemia in breast-vs formula-fed infants. Clin Pediatr 1985;24:69-73.

18. Johnson CA, Lieberman L, Hassenein E. The relationship of breast feeding to third day bilirubin levels. J Fam Pract 1985;20:147-52.

19. Osborn LM, Bolus R. Breast feeding and jaundice in the first week of life. J Fam Pract 1986;20:475-80.

20. Surjono A. Breast milk, weight loss and hyperbilirubinemia in fullterm newborn infants in the first week of life. Berkala I Kedokt 1993;1:42-8.

21. Bertini G, Dani C, Tronchin M, Rubaltelli FF. Is breastfeeding really favoring early neonatal jaundice? Pediatrics 2001;107:e41.

22. Gomella TL, Cunningham MD, Eyal FG. Neonatology: management, procedures, on-call problems, diseases and drugs. $3^{\text {rd }}$ ed. Connecticut: Appleton \& Lange; 1994. p. 311-23.

23. Amato M, Howald H, Muralt G. Fat content of human milk and breast milk jaundice. Acta Pediatr Scand 1985;74:805-6.

24. Poland RL, Schulz GE, Garg G. High lipase activity association with breast milk jaundice. Pediatr Res 1980;14:1328-31.

25. Surjono A. Total and unbound bilirubin concentration in Indonesian newborn infants. ICMR Annals 1986;6:53-9. 